\title{
Pengaruh Kuantitas Perojokan Dan Paparan Lingkungan Terhadap Mutu Benda Uji Beton Silinder
}

\author{
Sukobar ${ }^{1,}{ }^{*}$, Achmad Faiz ${ }^{1}$, Rachmad Basuki ${ }^{1}$, Dimas P. Dibiantara ${ }^{1}$, Dwi Indriyani ${ }^{1}$ \\ Departemen Teknik Infrastruktur Sipil, Fakultas Vokasi, ITS ${ }^{1}$ \\ Koresponden*,Email: kobarabiyil@gmail.com
}

\section{Info Artike}

Diperbaiki 19 September 2018

Disetujui 28 Desember 2018

Keywords: compression strength, cylindrical sample, mashing quantity, environmental exposure.
Kata kunci: kuat tekan, benda uji silinder, jumlah rojokan, paparan lingkungan.

\begin{abstract}
Concrete is a composite material for it is consisted of some other materials, being mixed until homogen and monolith. But, however the mixture diversification or certain compaction method are being done, there is chance of bubbles or air pores occurance who degrade the design strength. Furthermore, concrete curing holds an important role for preventing the rush of initial cracks. The emerging of initial cracks follow concrete's volume-shrinkage, which is led by fast evaporation and the hydration process. This study observed concrete's compression strength, represented by six type of mashing-quantity, 0, 5, 10, 15, 20, 25 times of mashing per layer. Each type is represented by two samples. Samples made are cylindrical with $150 \mathrm{~mm}$ in diameter and $300 \mathrm{~mm}$ in length. Material specification is conventional industrial concrete $\mathrm{K}$ 250 with 120 mm slump. Samples were made by single mixing in Indonesia's average weather and temperature. After being molded, samples were stored in environmental ambiance (exposed by direct sun-ray, wind, etc.). From the experimental research, we're achieving the optimum compression strength of 20 times mashing per layer-sample, 15,09 MPa. The exposure of environmental ambiance reduces $30 \%$ of concrete's design strength.
\end{abstract}

Beton merupakan material komposit karena terbentuk dari beberapa material lain yang diaduk sampai homogen dan monolit. Namun, meskipun sudah dilakukan diversifikasi bahan adukan maupun metode pemadatan tertentu, tetap ada kemungkinan adanya gelembung atau rongga udara yang mengurangi mutu beton rencana. Selain itu, perawatan juga memegang peranan penting karena mencegah timbulnya retak inisial pada beton. Kemunculan retak inisial ini akibat penyusutan volume beton karena air yang hilang dengan waktu yang relative singkat, ditambah lagi proses pengerasan beton merupakan proses hidrasi yang menimbulkan panas. Penelitian ini mengamati kuat tekan beton dengan enam tipe rojokan, 0, 5, 10, 15, 20, dan 25 kali rojokan untuk tiap lapisan. Setiap tipe rojokan diwakili oleh dua benda uji. Benda uji yang dibuat adalah silinder berdiameter $150 \mathrm{~mm}$ dan panjang $300 \mathrm{~mm}$. Spesifikasi material beton konvensional adalah mutu K-250 dengan nilai slump $120 \mathrm{~mm}$. Semua benda uji dibuat dari satu kali pencampuran beton pada iklim dan suhu rerata di Indonesia. Setelah dicetak, benda uji dibiarkan terpapar lingkungan (sinar matahari langsung, angin, dan sebagainya). Dari hasil penelitian ini didapatkan hasil bahwa kuat tekan optimum ada pada benda uji dengan 20 kali rojokan, yaitu 15,09 MPa. Paparan lingkungan mereduksi 30\% kuat tekan beton rencana.

\section{Pendahuluan}

SNI 2493-2011 tentang Tata Cara Pembuatan dan Perawatan Benda Uji di Laboratorium mensyaratkan perlakuan tertentu seperti pengujian slump untuk tiap batch adukan, perojokan dengan syarat tertentu, penggetaran, perawatan, dan lain sebagainya [1]. Perlakuan tersebut, yang dilakukan untuk menjamin ke-homogen-an dan ke-monolitan adukan beton segar, tidak disyaratkan dalam model pengecoran cast-in-situ atau setidaknya ada beberapa perbedaan perlakuan karena penyesuaian-penyesuaian tertentu.
Nilai pengujian slump, dalam peraturan terkait, menunjukkan kelecakan beton segar. Kelecakan beton segar sangat dipengaruhi oleh kandungan air dan/atau bahan tambahan lain yang berfungsi menggantikan air. Rentang nilai $\mathrm{pH}$ ideal dari air untuk campuran beton adalah antara 7,2 dan 7,6 [2]. Air yang digunakan dalam campuran beton juga harus bersih, bebas oli, asam, alkali, material organic, atau substansi pengotor lainnya [3-5]. Kelecakan beton diwakili oleh rasio air terhadap semen (w/c ratio), yaitu salah satu parameter yang mempengaruhi kualitas beton.

Beton merupakan material komposit karena terbentuk dari beberapa material lain yang diaduk sampai homogen dan 
monolit. Hal ini perlu dilakukan karena beton dalam analisisnya dianggap sebagai material homogen dengan parameter dan spesifikasi tertentu, sesuai dengan mix-design. Analisis mix-design menentukan komposisi agregat kasar, agregat halus, bahan pengikat, dan lain sebagainya. Kompleksitas tersebut dimaksudkan untuk meminimalisasi munculnya ruang-ruang atau gelembung-gelembung di dalam adukan beton. Selain itu, perojokan dan penggetaran juga dimaksudkan untuk memadatkan sekaligus meminimalisasi munculnya ruang-ruang atau gelembunggelembung udara di dalam adukan beton. Meski, bagaimanapun juga, beton mungkin saja akan memiliki ruang-ruang atau gelembung-gelembung udara karena pemadatan serta pengadukan yang kurang tepat, dimana hal tersebut secara signifikan mengurangi kekuatan beton [6] Peningkatan porositas mendegradasi kuat tekan, dalam hal ini, 20\% porositas menurunkan sekitar 34\% kuat tekannya [7]. Kepadatan beton dalam cetakan juga mempengaruhi kualitas beton, atau dengan kata lain, kepadatan beton berbanding lurus terhadap kekuatannya, hal ini juga didukung oleh salah satu peneliti [8]. Kepadatan sendiri didefinisikan sebagai suatu ukuran untuk mengetahui seberapa banyak partikel, dari suatu elemen atau material, yang mengalami desakan atau tekanan pada suatu dimensi ruang tertentu [9].

\section{Tinjauan Pustaka}

\section{a. Pembuatan Benda Uji (SNI 2493: 2011)}

Benda uji silinder yang dibuat di lapangan, dengan mengambil dari mesin pengaduk, harus berdiameter $150 \mathrm{~mm}$ dan panjang $300 \mathrm{~mm}$. Ukuran agregat kasar maksimum adalah 1/3 dari diameter benda uji.

Tabel 1. Spesifikasi pemadatan benda uji silinder

\begin{tabular}{ccc}
\hline & Pemadatan & Lapisan \\
\hline & & \\
\hline $300 \mathrm{~mm}$ & Penumbuk & 3 \\
$>300 \mathrm{~mm}$ & Penumbuk & Menyesuaikan \\
$\leq 460 \mathrm{~mm}$ & Penggetar & 2 \\
$>460 \mathrm{~mm}$ & Penggetar & 3 \\
\hline
\end{tabular}

Sumber: SNI 2493: 2011 ps. 7.3

Tabel 2. Spesifikasi penumbukan benda uji silinder

\begin{tabular}{ccc}
\hline $\begin{array}{c}\text { Diameter sampel } \\
\text { mm }\end{array}$ & $\begin{array}{c}\text { Diameter } \\
\text { penumbuk } \\
\text { mm }\end{array}$ & $\begin{array}{c}\text { Jml tumbukan tiap } \\
\text { lapis } \\
\text { mm }\end{array}$ \\
\hline $50-150$ & 10 & 25 \\
150 & 16 & 25 \\
200 & 16 & 50 \\
250 & 16 & 75 \\
\hline
\end{tabular}

Sumber: SNI 2493: 2011 ps. 7.4

Metode pemadatan beton segar dengan nilai slump $>75$ mm adalah dengan ditumbuk, untuk 25-75 mm adalah ditumbuk/digetar, dan untuk $<25 \mathrm{~mm}$ adalah digetar. Penumbukan dilakukan dengan memperhatikan keseragaman pada seluruh penampang cetakan, jumlah lapisan tumbukan, kemungkinan udara yang terperangkap, dan sebagainya.

Perawatan benda uji dilakukan untuk menghindari penguapan air dari beton segar yang belum mengeras. Benda uji dapat ditutupi dengan kain goni basah, pasir basah atau dengan merendamnya dalam air, sesuai kebutuhan. Cetakan dapat dibuka setelah 24 jam dan dapat diuji pada umur 7, 14, 21,28 , dan seterusnya.

\section{b. Regresi}

Tujuan dilakukannya regresi adalah untuk mengetahui sampai sejauh mana suatu variabel berhubungan dengan lainnya atau dengan beberapa variable lainnya [10]. Regresi membicarakan dua variable yakni $\mathrm{X}$ dan $\mathrm{Y}$. Perubahan variable $\mathrm{X}$ akan mengakibatkan perubahan pada variable $\mathrm{Y}$, tetapi perubahan pada variable $\mathrm{Y}$ tidak akan menyebabkan perubahan pada variable $X$.

Regresi Linier dapat dirumuskan sebagai berikut : $Y=a+b x$

$b=\frac{\Sigma x y}{\Sigma x^{2}}$

$a=\frac{\Sigma Y-b \Sigma X}{n}$

dimana:

$$
\begin{aligned}
& \Sigma x y=\Sigma X Y-\frac{\Sigma x \Sigma y}{n} \\
& \Sigma x^{2}=\Sigma X^{2}-\frac{(\Sigma X)^{2}}{n}
\end{aligned}
$$

\section{c. Kuat Tekan}

Kuat tekan suatu benda adalah besarnya beban yang bisa dipikul persatuan luas yang menyebabkan benda tersebut hancur. Selanjutnya, kuat tekan suatu benda persatuan luas disebut tegangan. Sehingga tegangan tekan dapat dirumuskan sebagai:

$$
\sigma=\frac{P}{A}
$$

dimana:

$$
\begin{aligned}
& \sigma=\text { tegangan tekan }\left(\mathrm{kg} / \mathrm{cm}^{2}\right) \\
& \mathrm{P}=\text { gaya atau beban tekan }(\mathrm{kg}) \\
& \mathrm{A}=\text { luas penampang }\left(\mathrm{cm}^{2}\right)
\end{aligned}
$$




\section{Metode}

Benda uji dalam penelitian ini menggunakan beton konvensional dari pabrikan dan dibuat di area pekerjaan lapangan dengan iklim dan suhu rata-rata wilayah di Indonesia. Spesifikasi beton segar adalah beton dengan mutu K-250, nilai slump $12 \mathrm{~cm}$, dan hanya sekali pencampuran untuk semua benda uji. Benda uji terdiri dari enam tipe berdasarkan jumlah rojokan tiap lapis, yaitu $0,5,10,15,20$, dan 25 rojokan. Setiap tipe jumlah rojokan terdiri dari dua benda uji.

Setelah dilepas dari cetakannya, semua benda uji diberi perlakuan perawatan yang sama seperti pekerjaan lapangan, yaitu beton dibiarkan terpapar lingkungan (sinar matahari langsung, angin, dan sebagainya). Pada umur beton 28 hari dilakukan pengujian tekan untuk semua tipe benda uji. Model perawatan serupa dilakukan oleh peneliti lain dengan penempatan benda uji dalam ruangan yang mampu mengatur suhu antara $0{ }^{\circ} \mathrm{C}-80{ }^{\circ} \mathrm{C}$ dan kelembapan udara relative antara 30\% RH sampai 98\% RH [11].

Hasil uji tekan menunjukkan pengaruh rojokan terhadap kuat tekan beton dan seberapa banyak penurunan kuat tekan yang terjadi pada beton akibat paparan lingkungan.

\section{Pembahasan}

Pengujian kuat tekan dilakukan di Laboratorium Material dan Struktur Gedung milik Departemen Teknik Infrastruktur Sipil, Fakultas Vokasi, ITS-Surabaya.

Hasil uji kuat tekan pada umur benda uji 28 hari adalah sebagai berikut:

\begin{tabular}{|c|c|c|c|c|c|c|}
\hline \multirow{2}{*}{$\begin{array}{c}\text { Benda } \\
\text { Uji } \\
\text { No. }\end{array}$} & \multirow{2}{*}{$\begin{array}{c}\text { Jml } \\
\text { rojok } \\
\text { an } \\
\end{array}$} & \multirow{2}{*}{$\begin{array}{c}\text { Berat } \\
\text { (Kg) }\end{array}$} & \multirow{2}{*}{$\begin{array}{l}\text { Beban Uji } \\
\operatorname{Max}(\mathrm{Kg})\end{array}$} & \multicolumn{3}{|c|}{ Tegangan Tekan } \\
\hline & & & & $\mathrm{kg} / \mathrm{cm}^{2}$ & \multicolumn{2}{|c|}{$\mathrm{N} / \mathrm{mm}^{2}$} \\
\hline 1 & 0 & 10,79 & 7700 & 43,57 & 4,27 & \multirow{2}{*}{5,74} \\
\hline 2 & 0 & 11,04 & 13000 & 73,56 & 7,21 & \\
\hline 3 & 5 & 11,82 & 20200 & 114,31 & 11,21 & \multirow{2}{*}{10,57} \\
\hline 4 & 5 & 11,52 & 17900 & 101,29 & 9,93 & \\
\hline 5 & 10 & 11,82 & 23200 & 131,29 & 12,87 & \multirow{2}{*}{11,27} \\
\hline 6 & 10 & 11,74 & 17400 & 98,46 & 9,66 & \\
\hline 7 & 15 & 11,74 & 14700 & 83,18 & 8,16 & \multirow{2}{*}{10,21} \\
\hline 8 & 15 & 11,88 & 22100 & 125,06 & 12,26 & \\
\hline 9 & 20 & 12,00 & 27300 & 154,49 & 15,15 & \multirow{2}{*}{15,09} \\
\hline 10 & 20 & 11,76 & 27100 & 153,35 & 15,04 & \\
\hline 11 & 25 & 11,68 & 23000 & 130,15 & 12,76 & \multirow{2}{*}{12,76} \\
\hline 12 & 25 & 11,78 & 23000 & 130,15 & 12,76 & \\
\hline Rata2 & & 11,63 & 19717 & 111,57 & & \\
\hline
\end{tabular}

Sumber: Hasil analisis

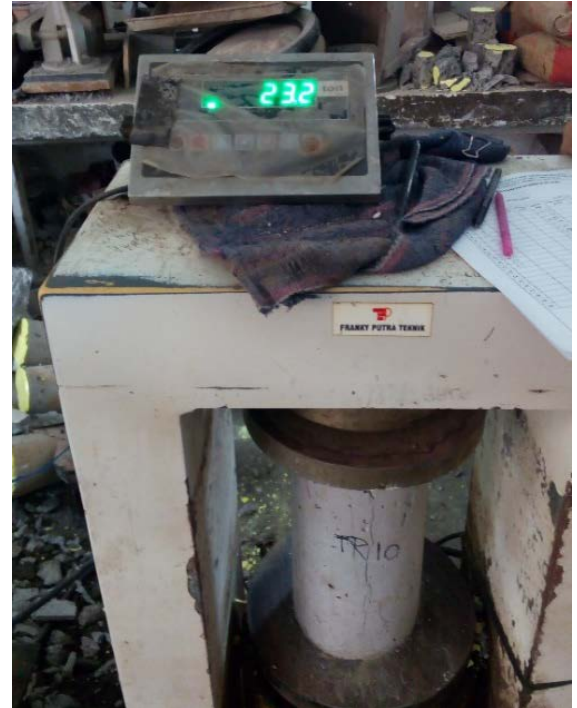

Gambar 1. Pengujian kuat tekan

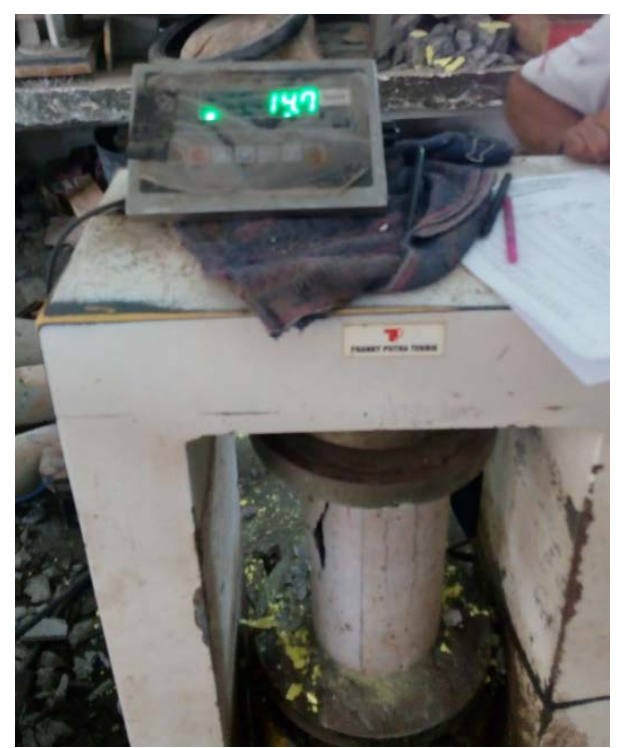

Gambar 2. Pengujian kuat tekan

Hasil uji tekan benda uji beton diplot pada grafik berikut, kemudian didekati dengan kurva parabolik pendekatan yang memiliki persamaan y $=7,2046 \mathrm{e}^{0,0293 x}$. Dari grafik tersebut, terlihat tren kurva yang menunjukkan kecenderungan peningkatan tegangan tekan benda uji dengan jumlah rojokan yang semakin banyak. Nilai optimumnya adalah 15,15 MPa dengan jumlah rojokan 20 kali tiap lapisnya. Rerata tegangan tekan benda uji tanpa rojokan adalah 5,74 MPa, jauh lebih kecil jika melihat rerata tegangan tekan benda uji dengan rojokan 25 kali, yaitu 15,09 MPa. Wahyudi et al. [8] menyimpulkan bahwa benda uji dengan perlakuan perojokan memiliki nilai kuat tekan yang lebih baik dibanding benda uji dengan perlakuan pemadatan menggunakan meja getar. Pemadatan beton segar penting untuk durabilitas dan 
kekuatan beton, bahkan, sedikit pemadatan pada beton segar akan mempengaruhi kuat tekannya [7]. Peraturan yang berlaku di Indonesia, dalam proses pembuatan benda uji silinder di lapangan (dengan dimensi tertentu), disarankan untuk melakukan perojokan sampai 25 kali per lapis [1].

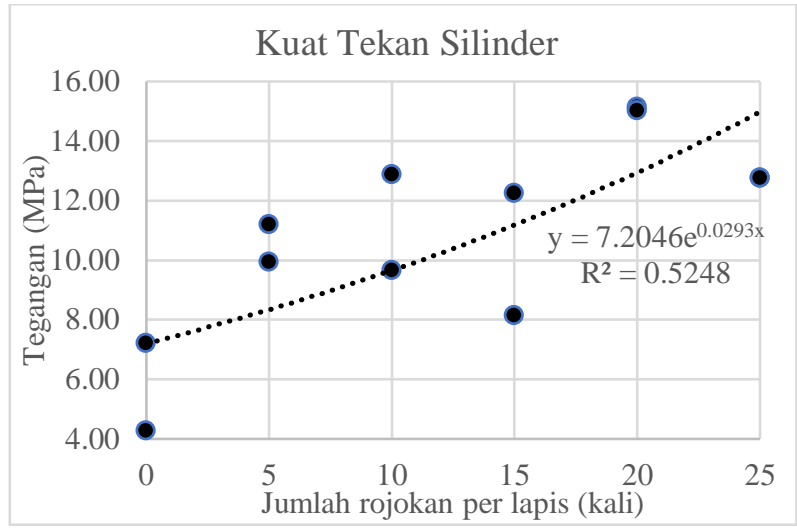

Gambar 3. Grafik parabolik kuat tekan silinder

Sedangkan untuk pendekatan regresi, persamaan yang didapat adalah $\mathrm{a}=7,54$ dan $\mathrm{b}=0$,272 dengan Standart Error 1,15 , maka persamaan garisnya dapat ditulis:

$$
y^{\prime}=7,54+0,272 x
$$

dimana:

$\mathrm{y}^{\prime}=$ tegangan tekan (MPa)

$\mathrm{x}=$ jumlah rojokan

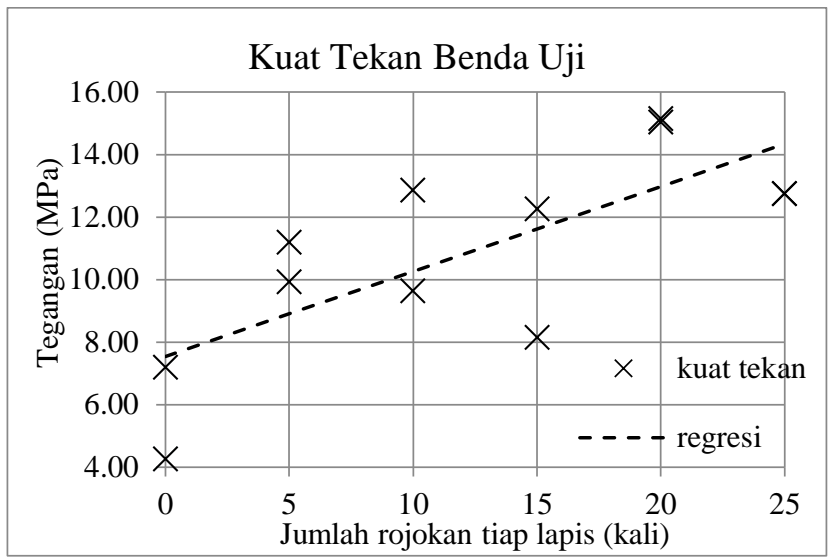

Gambar 4. Grafik regresi kuat tekan silinder

Pendekatan tegangan tekan beton pada jumlah rojokan 25 kali untuk kurva parabolic adalah sebesar 14,99 MPa, sedangkan untuk garis regresi linier adalah sebesar 14,34 MPa. Nilai ini lebih rendah dari tegangan tekan rencana yaitu K-250 (20,75 MPa). Hal ini menunjukkan bahwa beton tanpa perlakuan perawatan atau dibiarkan terpapar lingkungan (sinar matahari langsung, angin, dan sebagainya) hanya memiliki sekitar 70\% kuat tekan rencana K-250. Mi et al. [11] menyimpulkan bahwa penurunan kelembapan udara mentransformasikan mode keretakan beton dari perilaku daktail menjadi getas. Perubahan perilaku tersebut diterjemahkan sebagai penurunan kekuatan pada beton.

\section{Kesimpulan}

Dari pekerjaan yang sudah dilakukan beserta analisisnya, maka didapat:

1. Jumlah rojokan optimum untuk tiap lapisan adalah 20 kali, menghasilkan kuat tekan sebesar 15,09 MPa.

2. Analisis pendekatan regresi parabolic dan linier untuk jumlah rojokan 25 kali adalah 14,99 dan 14,34 MPa secara berurutan.

3. Persamaan regresi parabolik adalah $\mathrm{y}=7,2046 \mathrm{e}^{0,0293 \mathrm{x}}$

4. Persamaan regresi linier adalah $y^{\prime}=7,54+0,272 x$

Penurunan kuat tekan beton yang terpapar lingkungan (sinar matahari langsung, angin, dan lain sebagainya) adalah $30 \%$ dari kuat tekan rencana.

\section{Daftar Pustaka}

[1] Umum, D.P., Tata Cara Pembuatan dan Perawatan Benda Uji Beton di Laboratorium SNI 2493: 2011. 2011, Badan Standarisasi Nasional.

[2] Babu, G.R., B.M. Reddy, and N.V. Ramana, Quality of mixing water in cement concrete "a review". Materials Today: Proceedings, 2018. 5(1): p. 13131320.

[3] ASTM, C., 94, Standard Specification for Ready Mixed Concrete. 1916, American Society for Testing and Materials, West Conshohocken, PA.

[4] AASHTO, T., T 26-79. Standard method of test for quality of water to be used in concrete, 1979.

[5] Committee, A. Building code requirements for structural concrete:(ACI 318-99); and commentary (ACI 318R-99). 1999. American Concrete Institute.

[6] Mustafa Tuncan, Ö.A., Kambiz Ramyar, Bekir Karasu, Effect of Compaction On Assessed Concrete Strength. The IV. Ceramic, Glass, Enamel, Glaze and Pigment Seminar with International Participation (SERES 2007), 2007(Eskisehir, Turkey).

[7] Gonen, T. and S. Yazicioglu, The influence of compaction pores on sorptivity and carbonation of concrete. Construction and building materials, 2007. 21(5): p. 1040-1045.

[8] Wahyudi, W., I. Irwan, and N. Nurmaidah, Pengaruh Pemadatan Campuran Beton Terhadap Kuat Tekan K 175. JOURNAL OF CIVIL ENGINEERING, BUILDING AND TRANSPORTATION, 2017. 1(1): p. 37-53.

[9] Daukšys, M., et al., Influence of the concrete mixture compaction time on density and compressive strength of hardened concrete samples. 
Journal of Sustainable Architecture and Civil Engineering, 2015. 11(2): p. 79-87.

[10] Ritonga, A., Statistika Terapan Untuk Penelitian. Lembaga Penerbitan Fakultas Ekonomi UI, 1987.

[11] Mi, Z., et al., Effect of curing humidity on the fracture properties of concrete. Construction and Building Materials, 2018. 169: p. 403-413. 
